\title{
Melanin Concentrating Hormone (MCH): Structure-Function Aspects of Its Melanocyte Stimulating Hormone-Like (MSH-Like) Activity
}

\author{
TERRY O. MATSUNAGA,* VICTOR J. HRUBY, ${ }^{1}$ MICHAL LEBL, $\dagger$ \\ ANA MARIA DE LAURO CASTRUCCI AND MAC E. HADLEY§ \\ Departments of *Chemistry and \$Anatomy, University of Arizona, Tucson, AZ 85721 \\ tDepartment of Chemistry, Institute of Organic Chemistry and Biochemistry \\ Czechoslovak Academy of Sciences, Prague 6, CS166 10, Czechoslovakia \\ $\ddagger$ Departamento de Fisiologia, Instituto de Biociencias \\ Universidade de Sao Paulo CP 11176, Sao Paulo, 05499, Brazil
}

Received 6 February 1989

\begin{abstract}
MATSUNAGA, T. O., V. J. HRUBY, M. LEBL, A. M. DE LAURO CASTRUCCI AND M. E. HADLEY. Melanin concentrating hormone (MCH): Structure-function aspects of its melanocyte stimulating hormone-like (MSH-like) activity. PEPTIDES 10(4) 773-778, 1989. - Melanin concentrating hormone (MCH) is a heptadecapeptide, Asp-Thr-Met-Arg-Cys-Met-Val-Gly-Arg-ValTyr-Arg-Pro-Cys-Trp-Glu-Val, synthesized in the brain and secreted from the pars nervosa of teleost fish. This hormone stimulates melanosome (melanin granule) aggregation within integumental melanocytes of fishes but, in contrast, stimulates melansome dispersion within tetrapod (frog and lizard) melanocytes. We determined the message sequence of the primary structure of MCH which is responsible for its MSH-like component of activity. Removal of the $\mathrm{N}$-terminal amino acid results in an almost total loss of MSH-like activity. The C-terminal amino acid is also essential for full MSH-like activity since the analogue, MCH(1-16), is about 100 times less active than $\mathrm{MCH}$. Therefore, the entire heptadecapeptide sequence of $\mathrm{MCH}$ appears to contribute to the MSH-like activity of $\mathrm{MCH}$. Ring-contracted analogues (e.g., $\left[\mathrm{Ala}^{5}, \mathrm{Cys}{ }^{10}\right] \mathrm{MCH}$ ) of $\mathrm{MCH}$ are almost devoid of any melanosome aggregating (MCH-like) activity but generally possess considerable or as great an MSH-like activity as MCH. Racemization of MCH by heat-alkali treatment drastically reduces the $\mathrm{MCH}$-like activity of $\mathrm{MCH}$, but does not enhance the MSH-like activity of the hormone.
\end{abstract}

Melanin concentrating hormone $(\mathrm{MCH}) \quad$ Melanocyte stimulating hormone-like activity Structure-function aspects

MANY species of frogs, lizards, and fish are dependent upon hormonally-induced chromatic responses for their existence and survival. Two hormones, melanocyte concentrating hormone $(\mathrm{MCH})$ and $\alpha$-melanocyte stimulating hormone ( $\alpha-\mathrm{MSH})$, are primarily responsible for inducing skin lightening and skin darkening, respectively. $\mathrm{MCH}$ stimulates melanosome aggregation within melanocytes of teleost fish, and $\alpha-\mathrm{MSH}$ stimulates melanosome dispersion within melanocytes of most vertebrate species $(1,5,8$, $10,13,14) . \mathrm{MCH}$ is a heptadecapeptide with a centrally located disulfide bridge between residues 5 and 14 (Fig. 1).

It has been demonstrated that $\mathrm{MCH}$ can also promote the dispersion (MSH-like activity) of melansomes in both the frog and lizard skin bioassays $(21,22)$. The MSH-like activity of MCH has been confirmed by other laboratories as well $(7,12)$. Recently, ring-contracted $\mathrm{MCH}$ analogues were found to exhibit drastically reduced or no $\mathrm{MCH}$ activity (16). Interestingly, however, some analogues still retained MSH-like activity (16). Because of their dual activities, Castrucci and co-workers (6) have suggested a possible evolutionary link between the two hormones. Thus, from a common sequence, mutations could have resulted in two different peptides with different biological functions.

We have synthesized an entire series of $\mathrm{MCH}$ fragment analogues consisting of sequential deletions of either or both the $\mathrm{N}$ - and $\mathrm{C}$-termini. All of these truncated analogues still possessed the intact central cyclic disulfide bridge structure of $\mathrm{MCH}$. In a previous publication we reported on the $\mathrm{MCH}$-like activities of these fragment analogues as determined in fish skin bioassays (18). We concluded that the fragment analogue, $\mathrm{MCH}(5-15)$, is the minimal sequence for equipotency to $\mathrm{MCH}$ in the fish skin assay (eel, Synbranchus marmoratus). In the present report we

'Requests for reprints should be addressed to Victor J. Hruby. 
alph-iblanocyte Stimulating Hoceone (alphe-rsh) Ac-Ser-Tyr-Ser-Met-Glu-Hi s-Phe-Arg-Trp-Gly-Lys-Pro-Val-NH

melanocyte concentrating how one (MOH) Asp-Thr - Hot-Arg-Cyz-Aet-Val-Gly-Arg-Val-TYz-Arg-Pro-Cys-Trp-Glu-Val

FIG. 1. Primary structures of melanin concentrating hormone $(\mathrm{MCH})$ and melanocyte stimulating hormone ( $\alpha-\mathrm{MSH})$.

determined the MSH-like activities of the analogues as determined in the frog and lizard skin bioassays. The results reveal some of the structural aspects of $\mathrm{MCH}$ related to its $\mathrm{MSH}$ component of melanotropic activity.

\section{METHODS}

All peptides were synthesized using a modification of the method of Lebl and co-workers (16), as described by Matsunaga et al. (18). It should be noted that strict attention was paid to avoiding any contact with $\alpha-\mathrm{MSH}$ or any potent $\alpha-\mathrm{MSH}$ analogues. This necessitated thorough washing of all glassware with base followed by an acid wash, and then rinsing with distilled $\mathrm{H}_{2} \mathrm{O}$. All columns utilized were free of any exposure to $\alpha$-MSH or related peptides. As an added precaution, selected peptides were synthesized in a laboratory totally devoid of any synthesized melanotropins.

Frog skin assays were based upon previous work described in the literature $(3,11,19)$. Rana pipiens, a species of frog native to North American regions, were obtained from Kohn's Scientific Supply Company, Germantown, WI. Animals were sacrificed by decapitation and the leg and thigh skins were removed and kept viable in a bath of physiological saline (Ringer) solution. Skins were stretched over PVC rings and then baseline light reflectance was measured via a Photovolt (model 670) reflectometer. When stimulated by melanotropins, melansomes are induced to migrate from the perinuclear space throughout the dendritic processes of melanocytes. This leads to a generalized darkening of the entire skin. Since skin darkening results in an increase in light absorbance, reflectance measurements yield a decrease in reflectance. Upon removal of the melanotropin (i.e.. by rinsing with Ringer solution) a reaggregation of melanosomes to the perinuclear space occurs, and the skins generally relighten to their original baseline values.

Racemization studies were conducted according to the procedures of Bool et al. (4) and Eberle et al. (7). Skin darkening was determined via photoreflectance as above. All data were compiled and analyzed by plotting the percent skin darkening vs. - log concentration.

\section{RESULTS}

Melanin concentrating hormone $(\mathrm{MCH})$ stimulates melanosome aggregation within teleost melanocytes but not within pigment cells of tetrapods (frogs and lizards). Rather, $\mathrm{MCH}$ exhibits MSH-like activity when used at high concentrations in tetrapods (Fig. 2). We previously demonstrated that $\mathrm{MCH}$, as well as the fragment analogue, $\mathrm{MCH}(1-14)$, possessed MSH-like activity whereas $\mathrm{MCH}(5-17)$ and the central cyclic sequence, MCH(5-14), did not. This suggested that the N-terminal $1-4$ sequence, or some component thereof, was responsible for the MSH-like activity of MCH. Synthesis of $\mathrm{MCH}$ analogues with N-terminal deletions revealed that removal of the terminal amino acid resulted in a near total loss of $\mathrm{MSH}$-like activity relative to $\mathrm{MCH} . \mathrm{MCH}(2-17), \mathrm{MCH}(3-17)$ and $\mathrm{MCH}(4-17)$ exhibited greatly

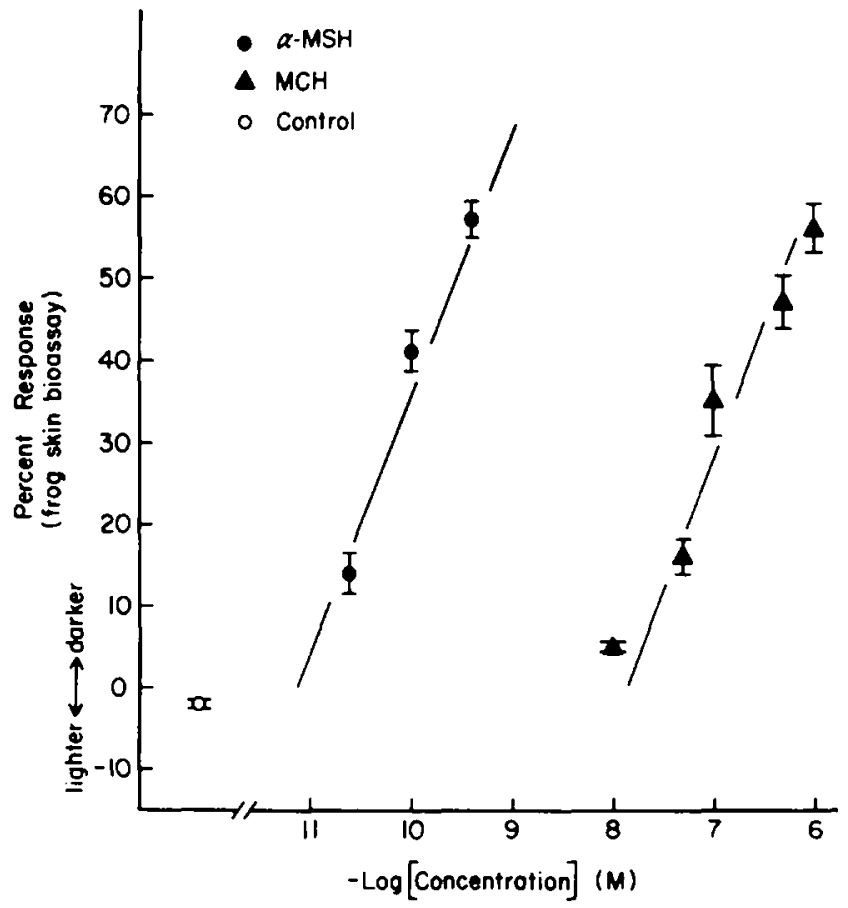

FIG. 2. In vitro demonstration of the MSH-like activity of $\mathrm{MCH}$ as seen in the frog ( $R$. pipiens) skin bioassays. Each value is the mean, \pm S.E., darkening response of the skins to $\alpha-\mathrm{MSH}(\mathrm{N}=10)$ or $\mathrm{MCH}(\mathrm{N}=5)$ at the concentrations indicated.

diminished MSH-like activity in both the frog and the lizard (data not shown) skin bioassays (Fig. 3). At very high concentrations, these $\mathrm{MCH}$ analogues were full MSH-like agonists although they were more than 100-fold less active than MCH (Fig. 3). Although the melanotropic activity of MSH is rapidly reversed following

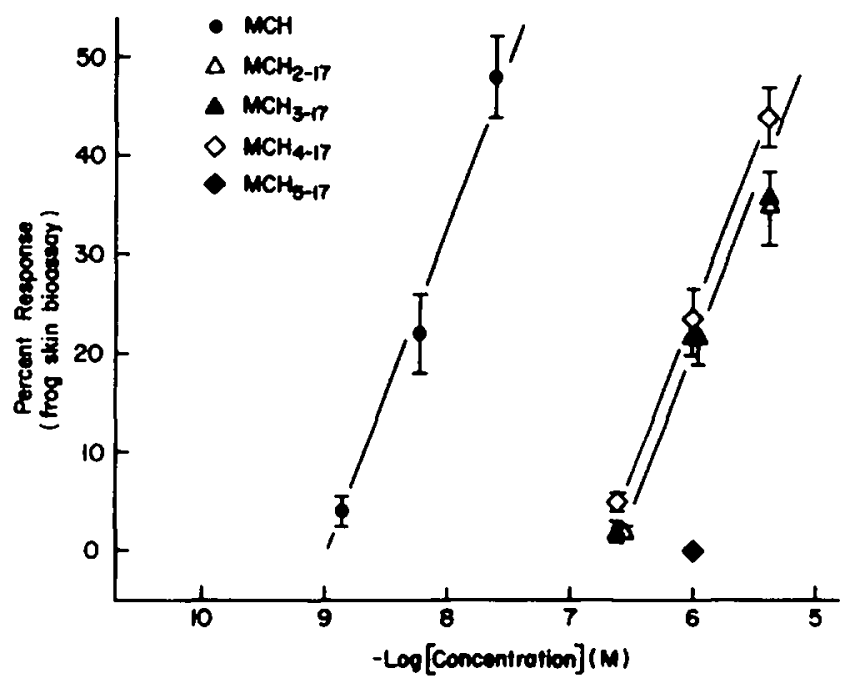

FIG. 3. $\mathrm{MCH}$ fragment analogues minus the first $[\mathrm{MCH}(2-17)]$, second [MCH(3-17)], third $[\mathrm{MCH}(4-17)]$, or fourth $[\mathrm{MCH}(5-17)]$ amino acid residues of the N-terminus lack of MSH-like activity. Each value is the mean, $\pm S$.E., darkening response of frog skins $(N=10)$ to the melanotropins at the concentrations noted. 


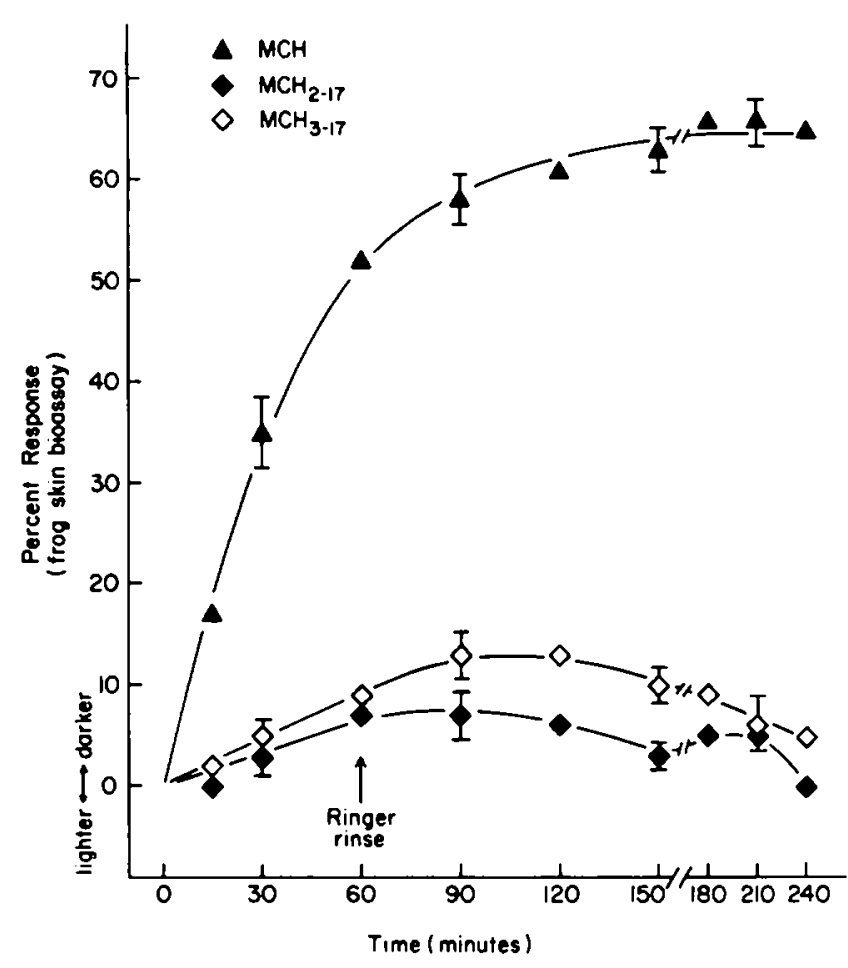

FIG. 4. In vitro demonstration that $\mathrm{N}$-terminal deleted fragment analogues of $\mathrm{MCH}$ have greatly reduced MSH-like potency. Following transfer of the skins to fresh Ringer in the absence of the peptides (Ringer rinse), the skins continued to remain darkened in response to $\mathrm{MCH}$ but not to the fragment analogues even over a long period of time. Each value is the mean, $\pm S$.E., darkening response of frog skins $(N=6)$ to the melanotropins $\left(10^{-6} \mathrm{M}\right)$.

transfer of frog or lizard skins to medium which lacks the hormone, the MSH-like activity of $\mathrm{MCH}$ is often prolonged in either species when used at high concentrations (Fig. 4). However,

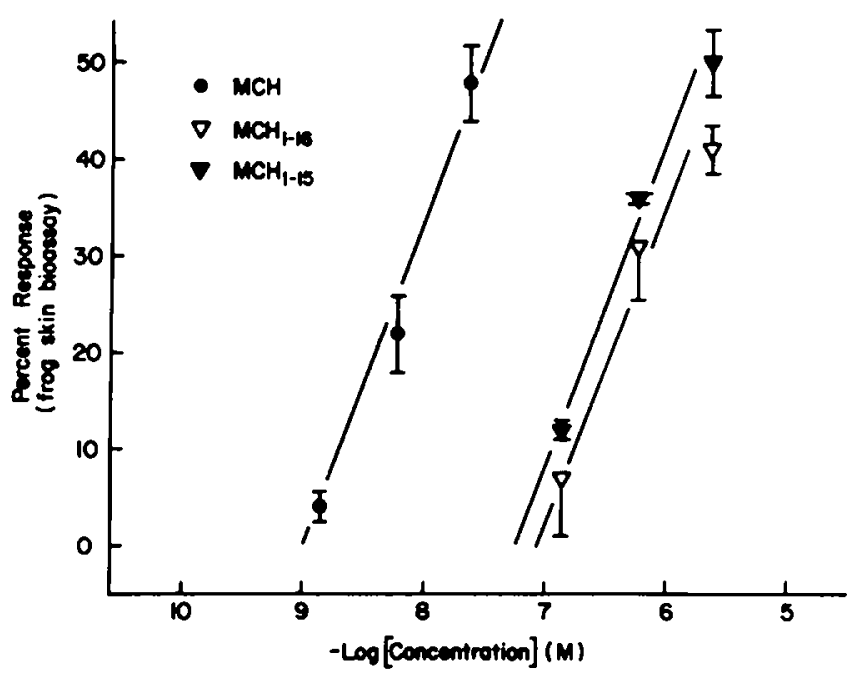

FIG. 5. In vitro demonstration that C-terminal deleted fragment analogues lacking C-terminal amino acids also lose considerable (compared to $\mathrm{MCH}$ ) MSH-like potency. Each value is the mean, \pm S.E., darkening response of lizard skins $(\mathrm{N}=6)$ to the melanotropins $\left(10^{-6} \mathrm{M}\right)$.
TABLE 1

RELATIVE POTENCIES OF MCH FRAGMENT ANALOGUES AS DETERMINED BY THE IN VITRO FISH (SYNBRANCHUS MARMORATUS) AND FROG (RANA PIPIENS) SKIN BIOASSAYS

\begin{tabular}{ccc}
\hline & Fish Skin Bioassay & Frog Skin Bioassay \\
PEPTIDE & Potency Relative to MCH & Potency Relative to MSH \\
\hline
\end{tabular}

$\mathrm{MCH}(1-17)$

$\mathrm{MCH}(2-17)$

$\mathrm{MCH}(3-17)$

$\mathrm{MCH}(4-17)$

$\mathrm{MCH}(5-17)$

$\mathrm{MCH}(1-16)$

$\mathrm{MCH}(2-16)$

$\mathrm{MCH}(3-16)$

$\mathrm{MCH}(4-16)$

$\mathrm{MCH}(5-16)$

$\mathrm{MCH}(1-15)$

$\mathrm{MCH}(2-15)$

$\mathrm{MCH}(3-15)$

$\mathrm{MCH}(4-15)$

$\mathrm{MCH}(5-15)$

$\mathrm{MCH}(1-14)$

$\mathrm{MCH}(2-14)$

$\mathrm{MCH}(3-14)$

$\mathrm{MCH}(4-14)$

$\mathrm{MCH}(5-14)$

$\begin{array}{ll}1.0 & \\ 1.0 & \\ 1.0 & \\ 1.0 & \\ 1.0 & (17) \\ 1.0 & \\ 1.0 & \\ 1.0 & \\ 1.0 & \\ 1.0 & \\ 1.0 & \\ 1.0 & \\ 1.0 & \\ 1.0 & \\ 1.0 & \\ 0.1 & {[0.07(17)]} \\ 0.07 & \\ 0.05 & \\ 0.023 & \\ 0.014 & {[0.003(17)]}\end{array}$

0.001

0.000005

0.000005

0.000005

$<0.000001$

0.00003

0.000005

0.00004

0.00001

0.000007

0.00003

0.00001

0.00001

0.000004

0.000004

0.000006

0.000005

$<0.000001$

$<0.000001$

$<0.00000$ 1 even over a long period of incubation these analogues failed to exhibit prolonged activity on frog melanocytes (Fig. 4). $\mathrm{MCH}$, as it had done previously, maintained its prolonged activity (Fig. 4).

Most fragment analogues of $\mathrm{MCH}$, like the parent hormone, possessed some MSH-like activity when used at high concentrations (e.g., $10^{-5} \mathrm{M}$ ). Removal of the C-terminal amino acid, Val, from $\mathrm{MCH}$ resulted in a peptide, $\mathrm{MCH}(1-16)$, which exhibited about $1 / 100$ the MSH-like activity of $\mathrm{MCH}$ (Fig. 5). The shorter C-terminal deleted fragment analogues, $\mathrm{MCH}(1-15)$ and $\mathrm{MCH}(1-$ 14), also exhibited a similar diminished MSH-like activity (Fig. 5; Table 1); $\mathrm{MCH}(1-14)$ showing the more drastic decrease in activity (Table 1). Thus, removal of residues from either the amino or carboxy termini led to reductions of melanotropic activity of at least two orders of magnitude relative to $\mathrm{MCH}$. One may note that in Table 1 , the most active fragment analogue is but $1 / 20.000$ the potency of $\alpha-\mathrm{MSH}$. Even using the most meticulous care, one cannot reliably assess the purity of a sample (from contamination) beyond this limit using current purification schemes. Hence, the very low in vitro potency may be an indication that these analogues could be even less potent or even completely inactive.

The melanotropic activity of $\alpha-\mathrm{MSH}$ (and $\beta-\mathrm{MSH}$ ) is enhanced by heat-alkali treatment (Fig. 6) (4). Heat-alkali treatment of $\alpha-\mathrm{MSH}$ also leads to a peptide that exhibits prolonged (residual) activity (Fig. 6). A recent report has suggested a similar result upon heat-alkali treatment of $\mathrm{MCH}$ (7). We have repeated the experiment and have found that heat-alkali treatment did not enhance the melanotropic activity of $\mathrm{MCH}$. In fact, we observed in several experiments a modest reduction in potency (Fig. 7).

\section{DISCUSSION}

These results clearly demonstrate that $\mathrm{MCH}$ possesses two contrasting melanotropic activities. The hormone stimulates mel- 


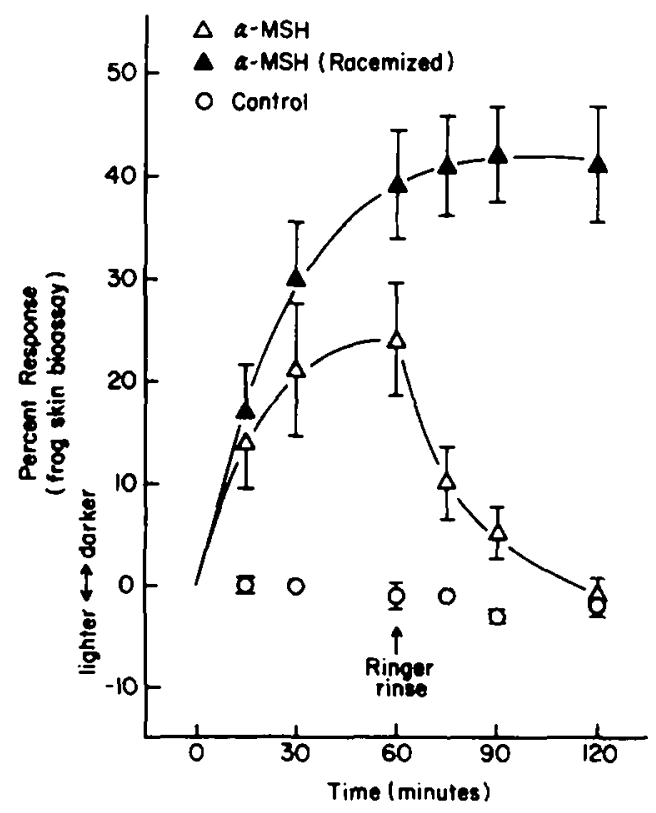

FIG. 6. In vitro demonstration that heat-alkali treatment (racemization) of $\alpha$-MSH leads to enhanced and prolonged biological activity. Each value is the mean, $\pm S$.E., darkening response of frog skins $(N=6)$ to $\alpha-M S H$ and to racemized $\alpha$-MSH $\left(10^{-10} \mathrm{M}\right)$.

anosome aggregation at physiological concentrations in teleost fishes and at higher concentrations stimulates melanosome dispersion within melanocytes of fishes, frogs and lizards.

Our original results demonstrated that some component of the $\mathrm{N}$-terminal tetrapeptide tail of $\mathrm{MCH}$ was necessary for MSH-like activity (9). That original observation was supported by our present study. Removal of the $\mathrm{N}$-terminal amino acid, aspartic acid, resulted in an analogue with an almost total lack of MSH-like activity relative to $\mathrm{MCH}$ (at $10^{-6} \mathrm{M}$ ) in both the frog and lizard skin bioassays. Not surprising, therefore, was the observation that

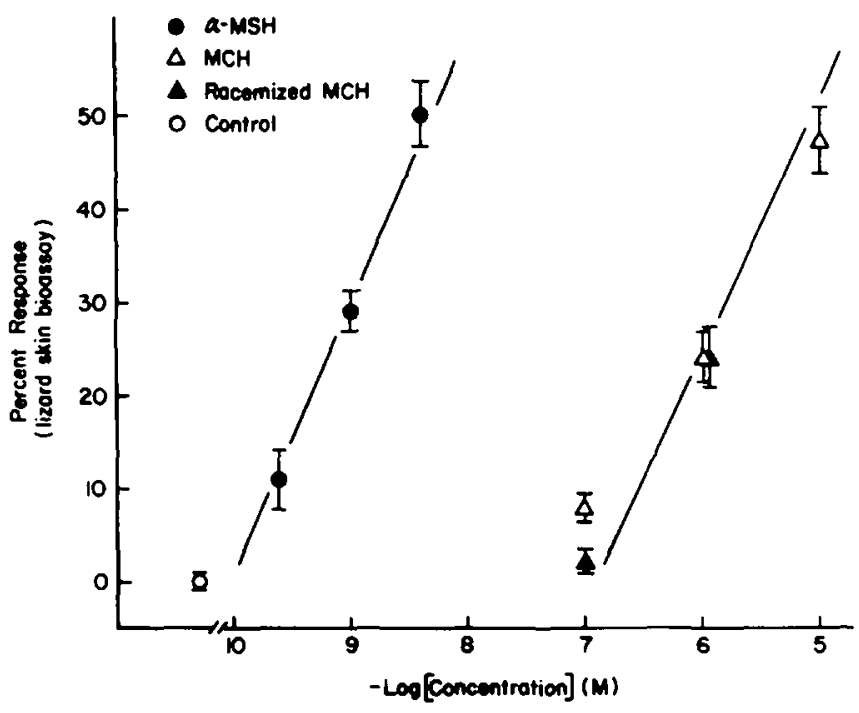

FIG. 7. In vitro demonstration that heat-alkali treatment of MCH does not enhance the MSH-like activity of the peptide. Each value is the mean. $\pm S$.E., darkening of the skins $(\mathrm{N}=6)$ at the concentrations noted. the $\mathrm{MCH}(3-17), \mathrm{MCH}(4-17)$ and $\mathrm{MCH}(5-17)$ analogues also showed decreased MSH-like activity (Fig. 2). Removal of the C-terminal amino acid residue also resulted in a dramatic (100fold) loss of MSH-like activity compared to $\mathrm{MCH}$ (Table 1). The C-terminal truncated peptides, $\mathrm{MCH}(1-14)$ and $\mathrm{MCH}(1-15)$, were even less potent than $\mathrm{MCH}(1-16)$. These results, taken together, suggest that the entire heptadecapeptide sequence of $\mathrm{MCH}$ contributes in some way to the MSH-like potency of the hormone.

Although the $\mathrm{N}$-terminal amino acid residue was essential for the full MSH-like activity of $\mathrm{MCH}$, all analogues, whether truncated at the $\mathrm{N}$ - or $\mathrm{C}$-termini, or both, exhibited some skin darkening (melanosome dispersion) when used at very high concentrations (i.e., $10^{-5} \mathrm{M}$ ). This was most dramatically demonstrated by Lebl and co-workers with a series of ring-contracted analogues (16). The most potent of these latter analogues was the analogue $\left[\mathrm{Cys}^{7}\right] \mathrm{MCH}(7-17)$. This peptide, particularly in the lizard skin bioassay, possessed the greatest MSH-like activity, being about 10 times more potent in that respect than $\mathrm{MCH}$ itself (17). Hence, manipulation of ring size has apparently resulted in conformational and/or topographical features that are less favorable for $\mathrm{MCH}$-like activity but, rather, more conducive to stimulating MSH-like activity.

Many years ago it was demonstrated that heat-alkali treatment of $\alpha$-MSH led to several phenomena relative to the melanotropic activity of the peptide: 1) retardation of response, 2) enhanced potency, and 3) prolonged activity (4,10). Since $\mathrm{MCH}$ exhibits MSH-like activity, the question arose as to whether similar changes could be induced following heat-alkali treatment of $\mathrm{MCH}$. Although the $\mathrm{MCH}$-like activity was drastically reduced (data not shown), no enhancement of the MSH-like activity of the hormone could be effected in $\mathrm{MCH}$ or several of its analogues. These observations were consistently observed. Therefore, we do not support the claim (7) that the MSH-like activity of $\mathrm{MCH}$ could be enhanced by heat-alkali treatment. In fact, with respect to our experiments, the MSH-like activity of $\mathrm{MCH}$ was modestly diminished.

In several other communications we have commented on the possible evolutionary relationships of $\alpha-\mathrm{MSH}$ and $\mathrm{MCH}$. It appears that the melanotropic activity (melanosome aggregation) of $\mathrm{MCH}$ is restricted to teleost fishes and their immediate forbearers (Holostean fishes). $\alpha-\mathrm{MSH}$, on the other hand, regulates melanosome dispersion and/or melanin synthesis in all species of vertebrates (including cartilaginous fishes and humans). Therefore, since the bony fishes were an early off-shoot from the main stem of vertebrate evolution, it might be assumed that MSH is ancestral to $\mathrm{MCH}$.

Since an MCH-like peptide is claimed to be present within the mammalian (including human) brain (23), an MCH-like peptide must have been present before the bony fishes evolved as an off-shoot of the mainline vertebrate evolution. Since MCH lacks MCH-like activity in all members of the tetrapod line, then it remains to be determined whether $\mathrm{MCH}$ or a related peptide plays some other physiological role in vertebrates.

Because of its ability to cause melanosome dispersion/aggregation, it is conceivable that $\mathrm{MCH}$ may have evolved by gene duplication of a melanotropin (e.g., $\alpha$ - or $\beta$-MSH, or ACTH) followed by mutations in one of the redundant MSH codons. On this note, we have compared the mRNA sequences for both $\alpha-\mathrm{MSH}$ and $\mathrm{MCH}$ (20) (Fig. 8). Although we could not readily find any significant amount of primary sequence homology either from sequence comparison, from changes due to possible frameshift mutations, or from residue deletions, one possibly interesting component did emerge. In $\alpha-\mathbf{M S H}$, structure-activity relationships have suggested the importance of $\mathrm{Phe}^{7}-\mathrm{Arg}^{8}(10)$ to its biological potency. In $\mathrm{MCH}$, Matsunaga et al. . have suggested the importance of the $\mathrm{Tyr}^{11}-\mathrm{Arg}^{12}-\mathrm{Pro}^{13}$ residues of $\mathrm{MCH}$. Interestingly, a 


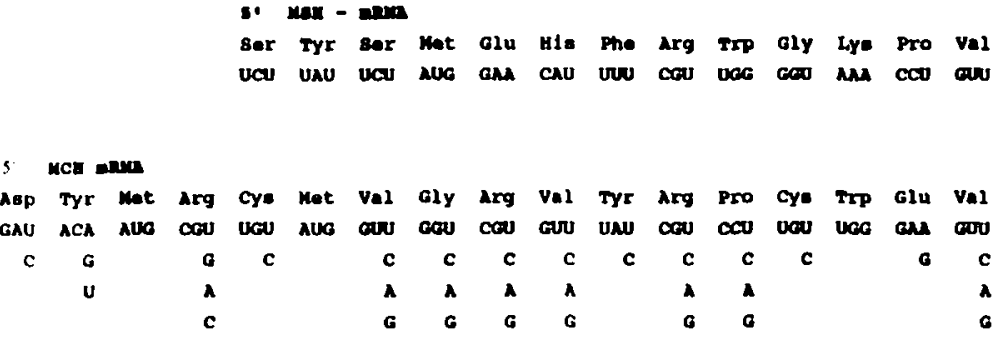

FIG. 8. Messenger RNA (mRNA) sequences of $\alpha-\mathrm{MSH}$ and $\mathrm{MCH}$.

point mutation of uracil to adenine for the Phe codon would convert the Phe to a Tyr (Fig. 8). If a point mutation had occurred precociously, this would imply that both $\mathrm{MCH}$ and $\alpha-\mathrm{MSH}$ would have had a Phe-Arg part of the sequence in common. This would be very interesting because this part of the sequence $\left(\mathrm{Phe}^{7}-\mathrm{Arg}^{8}\right.$ ) in $\alpha-\mathrm{MSH}$ and ( $\mathrm{Tyr}^{11}-\mathrm{Arg}^{12}$ ) in $\mathrm{MCH}$ is considered extremely important for their respective activities $(2,15,18)$. Certainly, it would be interesting to see if conversion of $\mathrm{Tyr}^{11}$ to $\mathrm{Phe}^{11}$ in $\mathrm{MCH}$ would lead to an increase in MSH-like activity. In addition, this would be interesting from an evolutionary standpoint. We currently are testing this hypothesis.

The fact that MCH has the ability to exhibit MSH-like activity leads one to consider a functional homology between the two peptides. In other words, there may be a topographical similarity in structure despite a lack of any primary sequence homologies. One may propose that the MSH-like activity of $\mathrm{MCH}$ could be due to the transducing component of the $\mathrm{MSH}$ receptor having a similar topology, but a different (binding) potency requirement than the $\mathrm{MCH}$ receptor (or vice versa). Alternatively, one could propose a common receptor that may be activated in different ways by $\mathrm{MCH}$ and $\alpha$-MSH. Although the second argument appears unlikely (9), neither proposal has been unequivocally ruled out.

\section{ACKNOWLEDGEMENTS}

This work was supported by U.S. Public Health Service (AM 17420 V.J.H.) and the National Science Foundation (DCB-8615706, M.E.H.), and by FAPESP $(87 / 0851-4)$ and by CNP $_{q}(407196 / 87,408683 / 88)$, Brazil (A.M.C.). The technical assistance of Mr. Michael Shea, Ms. Rachel Stover, Mr. Sean Sullivan, and the clerical assistance of Ms. Danielle DuBois are gratefully acknowledged. The authors also wish to acknowledge the Midwest Center for Mass Spectrometry, a National Science Foundation Regional Instrumentation Facility (Grant No. CEH 8211164). Terry O. Matsunaga wishes to thank the National Institute on Drug Abuse (NIDA) for a post-doctoral fellowship grant IF 05371-01.

\section{REFERENCES}

1. Baker, B. I.; Rance, T. A. Further observations on the distribution and properties of teleost melanin concentrating hormone. Gen. Comp. Endocrinol. 50:423-431; 1983.

2. Baker, B. I.: Eberle, A. N.: Bauman, J. B.; Siegrist, W.; Girard, J. Effect of melanin concentrating hormone on pigment and adrenal cells in vitro. Peptides 6:1125-1130; 1985

3. Bjorklund, A.; Meurling, P.: Nilsson, G.; Nobin, A. Standardization and evaluation of a sensitive and convenient assay for melanocyte stimulating hormone using Anolis skin in vitro. J. Endocrinol. 53:161-169; 1972.

4. Bool, A. M.; Gray, G. H.; Hadley, M. E.; Heward, C. B.; Hruby, V. J.; Sawyer, T. K.; Yang, Y. C. S. Racemization effects on melanocyte-stimulating hormones and related peptides. J. Endocrinol. 88: $57-65 ; 1981$.

5. Castrucci. A. M. L.: Hadley, M. E.: Hruby, V. J. A teleost skin bioassay for melanotropic peptides. Gen. Comp. Endocrinol. 66 374-380; 1987

6. Castrucci, A. M. L.; Hadley, M. E.; Wilkes, B. C.; Zechel, C.; Hruby, V. J. Melanin concentrating hormone exhibits both MSH and $\mathrm{MCH}$ activities on individual melanophores. Life Sci. 40:1845-1851; 1987.

7. Eberle, A. N.; Atherton, E.; Dryland, A.; Shepherd, R. C. Peptide synthesis. Part 9. Solid-phase synthesis of melanin concentrating hormone using a continuous flow polyamide method. J. Chem. Soc. Perkin Trans. 1:361-367; 1986.

8. Enami, M. Melanophore-concentrating hormone $(\mathbf{M C H})$ of possible hypothalamic origin in the catfish, Parasilurus. Science 121:36-37: 1955

9. Hadley. M. E.; Zechel, C.: Wilkes. B. C.: Castrucci, A. M. L.; Visconti, M. A.; Pozo-Alonso, M.; Hruby, V. J. Differential structural requirements for the $\mathrm{MSH}$ and $\mathrm{MCH}$ activities of melanin concentrating hormone. Life Sci. 40:1139-1145; 1987.

10. Hruby, V. J.; Wilkes, B. C.; Cody, W. L.; Sawyer. T. K.; Hadley, M. E. Melanotropins: Structural, conformational, and biological considerations in the development of superpotent and superprolonged analogs. In: Hearn, M. T. W., ed. Peptide protein review, vol. 3 New York: Marcel Dekker, Inc.; 1984:1-64.

11. Huntington, T.; Hadley, M. E. Evidence against mass action direct feedback control of melanophore-stimulating hormone (MSH) release. Endocrinology 95:472-479; 1974

12. Ide, H.: Kawazoe, I.; Kawauchi, H. Fish melanin concentrating hormone disperses melanin in amphibian melanophores. Gen. Comp. Endocrinol. 58:486-490; 1985.

13. Imai, K. Extraction of melanophore concentrating hormone (MCH) from the pituitary of fishes. Endocrinol. JPN 5:34-48; 1958.

14. Kawauchi, H.; Kawazoe, M.; Tsubokawa, M.; Kishida, M.; Baker, B. I. Characterization of melanin concentrating hormone in chum salmon pituitaries. Nature 305:321-323; 1983.

15. Kawazoe, I.; Kawauchi, H.; Hirano, T.; Naito, N. Structure-activity relationships of melanin-concentrating hormone. Int. J. Pept. Prot. Res. 29:714-721; 1987

16. Lebl, M.; Hruby, V. J.; Castrucci, A. M. L.; Visconti, M. A.; Hadley, M. E. Melanin concentrating hormone analogues: contraction of the cyclic structure. 1. Agonist activity. J. Med. Chem. 31: 949-953; 1988.

17. Lebl, M.; Hruby, V. J.; Castrucci, A. M. L.; Hadley, M. E. Melanin concentrating hormone $(\mathrm{MCH})$ analogues: Contraction of the cyclic structure. II. Antagonist activity. Life Sci. 44:451-457; 1989.

18. Matsunaga, T. O.; Castrucci, A. M. L.; Hadley, M. E.; Hruby, V. J. Melanin concentrating hormone (MCH): Synthesis and bioactivity studies of MCH fragment analogues. Peptides 10:349-354; 1989.

19. Shizume, K.; Lemer, A. B.; Fitzpatrick, T. B. In vitro bioassay for the melanocyte stimulating hormone. Endocrinology 54:553-560 1954.

20. Stryer, L. In: Biochemistry. New York: W. H. Freeman and Co.; 1988:91-116.

21. Wilkes, B. C.; Hruby, V. J.; Sherbrooke, W. C.; Castrucci, A. M. L.; Hadley, M. E. Synthesis and biological actions of melanin concentrating hormone. Biochem. Biophys. Res. Commun. 122:613-619; 1984. 
22. Wilkes, B. C.: Hruby, V. J.; Castrucci, A. M. L.; Sherbrookc, W. C.: Hadley, M. E. Synthesis of a cyclic melanotropic peptide exhibiting both melanin-concentrating and -dispersing activities. Science 224: $1111-1113 ; 1984$
23. Zamir. N.; Skofitsch. G.; Bannon, M. J.; Jacobowitz, R. M. Melanin-concentrating hormone: unique peptide neuronal system in the rat brain and pituitary gland. Proc. Natl. Acad. Sci. USA 83:1528-1531: 1986 